\title{
Prescrição de tecnologia assistiva para alunos com deficiência física: uma investigação com professores de salas de recursos multifuncionais
}

\author{
Maria Carolina Pereira e Castro Perez* \\ Mariana Dutra Zafani** \\ Luciana Ramos Baleotti***
}

\section{Resumo}

O Atendimento Educacional Especializado (AEE) é realizado nas Salas de Recursos Multifuncionais (SRM) que são equipadas com recursos da Tecnologia Assistiva (TA). Para o uso eficaz desses recursos faz-se necessário que o professor do AEE tenha conhecimentos prévios que subsidiem a sua utilização junto aos alunos com deficiência. Os objetivos deste estudo foram identificar o grau de satisfação do professor do AEE em relação a sua participação no processo que envolve o uso do recurso da TA; e a existência de parcerias com profissionais de outras áreas do conhecimento nesse processo. Participaram do estudo nove professoras de SRM todas com contato prévio com aluno com deficiência física (DF). Para a coleta de dados utilizou-se um questionário, constituído por três partes. Os resultados indicam que para o uso da TA junto ao aluno com DF a maioria das professoras mantém parceria com diferentes profissionais tais como fisioterapeutas, fonoaudiólogos e terapeutas ocupacionais. A falta de conhecimento e de capacitação continuada sobre recursos da TA, bem como a ausência de retorno por parte de alguns dos profissionais que mantém parceria, são os principais motivos que impactam negativamente na satisfação em relação ao uso da TA. Os resultados deste estudo trazem subsídios para a compreensão de aspectos que podem melhorar a eficácia do uso da TA no contexto educacional. Além disso, suscitam reflexóes sobre qual a maneira mais adequada de se efetivar parcerias colaborativas eficazes no âmbito educacional, as quais possam consequentemente, intensificar os seus benefícios para os alunos com deficiência.

Palavras-chave: Tecnologia assistiva; Sala de recursos multifuncionais;

Deficiência física.

\footnotetext{
* Graduada em Terapia Ocupacional pela Universidade Estadual Paulista Júlio de Mesquita Filho (UNESP), São Paulo, São Paulo, Brasil.

** Doutorado em Educaçáo pela Universidade Estadual Paulista Júlio de Mesquita Filho (UNESP), São Paulo, São Paulo, Brasil.

*** Doutora em Educaçáo pela Faculdade de Filosofia e Ciências(UNESP), São Paulo, São Paulo Brasil.
} 


\section{Assistive technology prescription for students with physical disability: a research with multifunctional resorce classes teachers}

\section{Abstract}

The Special Educational Service (SES) is performed in Multifunctional Resource Classes (MRC), which are equipped with Assistive Technology features (AT). For effective use of these resources, it is necessary that the SES teacher has the knowledge that supports its use with the students with disabilities. The objectives of this study were to identify the degree of the SES teacher satisfaction regarding their participation in the process involving the AT resource use and the existence of partnerships with professionals from other fields of knowledge in the process. The study included nine MRC teachers, all of them with prior contact with students with physical disabilities (PD). For data collection was used a questionnaire, constituted by three parts. The results indicate that for AT use on a PD student, the majority of teachers maintain partnerships with other professionals like physical therapists, speech therapists and occupational therapists. The lack of knowledge and the lack of continuous training about features of AT, as well as the absence of feedback from some professionals that maintain partnerships are the main reasons that negatively impact on AT use satisfaction. The results of this study contribute to the comprehension of aspects which can improve the efficiency of AT use in the educational context. Furthermore, it arises reflection about which way is more appropriate to carry effective collaborative partnerships in the educational scope, which may intensify their benefits for students with disabilities.

Keywords: Assistive Technology; Multifunctional Resource Rooms; Physical Disability.

\section{Introdução}

Com base na perspectiva da educação inclusiva, o Brasil assumiu o compromisso de assegurar o acesso e permanência da diversidade de alunos no ensino regular, e de adotar medidas que garantam as condiçôes para a efetiva participação deles (BRASIL, 2008). Nesse contexto, a Educação Especial passa a ressignificar o seu papel, de um sistema educacional especializado à parte do ensino comum para "[...] um conjunto de metodologias, recursos e conhecimentos (materiais, pedagógicos e humanos) que a escola comum deverá dispor para atender à diversidade de seu alunado" (GLAT; PLETSCH; FONTES, 2007, p. 345). Portanto, a Educação Especial passa a ter caráter complementar e/ou suplementar, transversal a todas as modalidades e níveis de ensino. Esse caráter implicou mudanças determinantes que resultaram na atual caracterização do Atendimento Educacional Especializado (AEE), voltado para os alunos público-alvo da Educação Especial (GIROTO, 2014). 
De acordo com a Resolução no 4 do Conselho Nacional de Educação (BRASIL, 2010, p. 10) o AEE caracteriza-se por atendimento "[...] ofertado em salas de recursos multifuncionais ou em centros de AEE da rede pública ou de instituiçóes comunitárias, confessionais ou filantrópicas sem fins lucrativos". As salas de recursos multifuncionais (SRM) compreendem "[...] ambientes dotados de equipamentos, mobiliários e materiais didáticos e pedagógicos para a oferta do atendimento educacional especializado" (BRASIL, 2011, p. 24).

"Para atuação no AEE, o professor deve ter formação inicial que o habilite para o exercício da docência e formação específica na educação especial, inicial ou continuada (BRASIL, 2009, p. 3). De acordo com o Art. $13^{\circ}$ da Resoluçáo no 4/2009 (BRASIL, 2009) o professor, responsável pelo AEE, tem diversas atribuiçôes, dentre elas destacam-se aquelas relacionadas aos recursos da Tecnologia Assistiva (TA). O uso da TA atualmente encontra-se em ascensão, em função, sobretudo, de a TA facilitar a participação das pessoas com deficiência nos diferentes contextos sociais, dentre eles a escola (RODRIGUES; ALVES, 2013). "Na área educacional, a Tecnologia Assistiva vem se tornando, cada vez mais, uma ponte para abertura de novo horizonte nos processos de aprendizagem e desenvolvimento de alunos com deficiências até bastante severas" (GALVÃO FILHO, 2009, p. 149).

A Tecnologia Assistiva é de característica interdisciplinar, engloba serviços e recursos que buscam promover a funcionalidade de pessoas com deficiência, promovendo a sua autonomia, independência, qualidade de vida e inclusão social (COMITÊ DE AJUDAS TÉCNICAS, 2009).

Nesse quesito, o professor tem como tarefa identificar, elaborar, produzir recursos, acompanhar a funcionalidade e a aplicabilidade desses recursos na sala de aula regular, e em outros ambientes da escola. Deve também estabelecer parcerias com as áreas intersetoriais na elaboração de estratégias e na disponibilização dos recursos, orientar professores e famílias acerca dos recursos utilizados pelo aluno; ensinar e usar a TA de forma a ampliar habilidades funcionais dos alunos, promovendo autonomia e participação (BRASIL, 2009).

Constata-se que ao professor do AEE cabe a responsabilidade de conhecer, de forma abrangente, os mais variados recursos pedagógicos e de TA que visam atender de forma eficaz àqueles que deles necessitam. Além disso, precisa relacionar esse conhecimento às características físicas, sensoriais e intelectuais da diversidade de alunos a serem atendidos. Com relação aos alunos que podem se beneficiar do AEE há aqueles com deficiência física, a qual se caracteriza por:

alteração completa ou parcial de um ou mais segmentos do corpo humano, acarretando o comprometimento da funçáo física, apresentando-se sob a forma de paraplegia, paraparesia, monoplegia, monoparesia, tetraplegia, tetraparesia, triplegia, triparesia, hemiplegia, hemiparesia, ostomia, amputação ou ausência de membro, paralisia cerebral, nanismo, membros com deformidade congênita ou adquirida, exceto as deformidades estéticas e as que não produzam dificuldades para o desempenho de funçôes. (BRASIL, 2004, p. 12). 
Para que o aluno com deficiência física possa participar ativamente das atividades escolares, algumas medidas poderão ser necessárias a fim de adequar as condições de ensino às características do aluno. Segundo Ghedini, Mancini e Brandão (2010) a participação do aluno com deficiência física no ambiente escolar está vinculada a diferentes fatores, como às habilidades motoras da criança, a acessibilidade física aos espaços escolares e as demandas das diferentes atividades. Ao considerar que o professor é o ator principal do processo inclusivo é essencial que esteja preparado para atuar junto aos alunos com deficiência física atendendo suas necessidades educacionais especiais (MELO; PEREIRA, 2013).

No entanto, a literatura, de longa data, tem apontado que o professor se sente despreparado para lidar com alunos com deficiência física, bem como para utilizar a TA junto a esses alunos, e evidenciado a necessidade de parcerias com profissionais de outras áreas de conhecimento (ROCHA; LUIZ; ZULIAN, 2003; VITTA; SILVA; MORAES, 2004). Há relatos também de sentimentos negativos como impotência, frustração e despreparo (ANJOS; ANDRADE; PEREIRA, 2009).

Os resultados de um estudo realizado por Pelosi e Nunes (2009) com 29 professores itinerantes da área da deficiência física indicaram que $70 \%$ deles consideravam a TA fundamental para o processo de inclusão. Com relação às parcerias estabelecidas com profissionais da Saúde os resultados mostraram que os professores tinham parcerias com psicólogos (37\%), fisioterapeutas (27\%), terapeutas ocupacionais $(18 \%)$ e fonoaudiólogos (12\%). Os professores tinham opiniōes positivas e negativas a respeito das parcerias estabelecidas. As opinióes positivas referiam-se à evolução do aluno, a confiança do professor para atuar com o aluno com deficiência física, confeccionar adaptaçôes e orientaçóes ao professor da turma. Com relação às opiniốes negativas, estas se deram pela dificuldade no relacionamento e divergência de orientaçôes advindas dos diversos profissionais quanto ao posicionamento na postura sentada e o uso de recursos e mobiliários adaptados.

No estudo desenvolvido por Sameshima (2011) professores do Ensino Fundamental relataram que tiveram dificuldade na elaboração e preparação do material pedagógico para que os alunos com deficiência física pudessem participar das tarefas em sala de aula. A dificuldade relatada se deu em funçấo do desconhecimento dos recursos disponíveis para esses alunos.

Paula e Baleotti (2011) em um estudo realizado com uma professora da Educação Infantil concluíram que as necessidades da professora, relacionavam-se, principalmente, a falta de recursos pedagógicos adaptados, a ausência de mobiliário adequado às condiçóes motoras do aluno e a falta de apoio de profissionais da área da saúde, cujo conhecimento possibilita-lhes atuar como parceiros no processo de inclusão escolar.

Em outro estudo, tanto professores da Educação Infantil quanto do primeiro ao quarto ano do Ensino Fundamental enfatizaram que encontraram limitaçôes relativas à formação profissional para lidar com as características do quadro clínico do aluno com deficiência física, e para identificar as possibilidades de aprendizagem des- 
se aluno. Além disso, destacaram outros aspectos que exercem impacto sobre a prática pedagógica, dentre eles, a falta de conhecimento de recursos pedagógicos e materiais escolares adaptados, e falta de apoio de profissional especializado (ZAFANI, 2013).

A TA, no contexto educacional, representa uma alternativa que pode favorecer a participação do aluno com deficiência física nas atividades desenvolvidas em sala de aula regular, tendo como mediador, o professor do AEE. Para tanto, é importante que esse professor se aproxime do professor da sala regular e dos demais profissionais que fazem interface com a Educação tais como terapeutas ocupacionais, fisioterapeutas e fonoaudiólogos. A aproximação com esses profissionais pode favorecer a interlocução com outras áreas do conhecimento, de maneira a buscar estratégias conjuntas que viabilizem a operacionalização e o uso dos recursos de TA.

Os estudos aqui apresentados remetem à discussão sobre a importância de o professor receber orientaçôes quanto aos aspectos relativos à condição da deficiência física, bem como aos recursos da TA que podem ser utilizados em sala de aula e, consequentemente, contribuir para a prática da inclusão escolar. Porém, a maioria dos estudos da área da Educação Especial que abordou a temática da TA foi realizada com professores do ensino regular. Há escassez de estudos que objetivem investigar a percepção do professor do AEE sobre o uso da TA no processo educacional do aluno com deficiência física.

Frente ao exposto, e considerando a relevância dos professores do AEE no processo educacional de alunos com deficiência e nas atribuições que lhe são conferidas relativas a TA, é de extrema importância considerar as opinióes e as necessidades desses professores. Estas podem trazer subsídios para fomentar as reflexōes e discussôes acerca da sistematização de açóes relativa à prescrição, acompanhamento e/ou parcerias que podem tornar o uso da TA eficaz e, assim, contribuir para o processo de escolarização de alunos com deficiência física.

\section{Objetivos}

Os objetivos deste estudo consistiram em identificar o grau de satisfaçáo do professor do AEE em relação a sua participaçáo no processo que envolve o uso do recurso da TA; e a existência de parcerias com profissionais de outras áreas do conhecimento nesse processo.

\section{Método}

Este estudo foi aprovado pelo Comitê de Ética em Pesquisa da Faculdade de Filosofia e Ciências, Unesp, Campus de Marília, Processo no 1.054.282.

Participaram nove professoras de onze salas de recursos multifuncionais (SRM) localizadas em escolas municipais de uma cidade de médio porte do interior paulista. Registra-se que duas, dessas nove professoras, atuavam em duas SRM. Todas eram graduadas em Pedagogia, do sexo feminino, na faixa etária entre 27 e 40 anos. Sete professoras tinham formação continuada na área da Educação Especial, sendo Habilitação em Deficiência Intelectual (P2, P3 e P9), em Deficiência Física (P6), 
em Psicopedagogia (P6 e P7) e, Especialização em Educação Especial (P1 e P4). O critério de inclusão no estudo atendeu ao quesito contato prévio com aluno com deficiência física.

A coleta de dados se deu individualmente, no mês de abril de 2015, em um único encontro, com duração de aproximadamente 20 minutos. A coleta foi feita nas salas em que essas professoras atuavam. Utilizou-se um questionário contendo perguntas abertas e fechadas, o qual é constituído por três partes. A primeira parte tem como finalidade coletar dados referentes à caracterização dos professores, como: dados pessoais, formação e tempo de atuação na educação. A segunda parte visa verificar o grau de satisfação do professor no processo de seleçáo, indicaçáo, treinamento e acompanhamento do uso do recurso de TA por aluno com deficiência física. Essa parte é composta por seis alternativas de resposta, sendo: satisfeito, pouco satisfeito, pouco insatisfeito, insatisfeito, muito insatisfeito, náo faz uso de TA. O respondente deve optar por uma dessas alternativas de respostas e, em seguida, justificar o motivo de sua escolha. A terceira e última parte do questionário busca identificar a existência de parceria com profissionais de outras áreas do conhecimento no processo que envolve o uso do recurso da TA. Nessa parte, os participantes devem assinalar a opçáo sim ou não. Caso assinalem a opção sim, há espaço para indicar o profissional e/ou profissionais com os quais mantêm parceria.

As respostas foram inseridas em um banco de dados do Excel e tabuladas para verificar a frequência das alternativas de resposta dada a cada questão. Posteriormente, foram analisadas qualitativamente, em busca de respostas que justifiquem o sentimento de satisfação ou insatisfação dos professores em relação ao uso da TA junto ao aluno com deficiência física.

\section{Resultados e Discussão}

Para melhor entendimento dos resultados obtidos, considerou-se pertinente apresentar a caracterizaçáo dos alunos com DF, a qual se encontra descrita no quadro abaixo.

Quadro 1 - Caracterização dos alunos com DF

\begin{tabular}{|l|l|l|l|l|l|}
\hline Professor & aluno & sexo & Diagnóstico & Série escolar & TA utilizada \\
\hline P1 & A1 & M & $\begin{array}{l}\text { 1PC - } \\
\text { hemiparesia } \\
\text { esquerda }\end{array}$ & 5o ano-2 EF & $\begin{array}{l}\text { Plano inclinado, } \\
\text { tesoura mola. }\end{array}$ \\
\hline P2 & A2 & M & $\begin{array}{l}\text { PC hemiparesia } \\
\text { esquerda }\end{array}$ & EF & $\begin{array}{l}\text { Plano inclinado, } \\
\text { lápis engrossado, } \\
\text { tesoura adaptada. }\end{array}$ \\
\hline
\end{tabular}




\begin{tabular}{|c|c|c|c|c|c|}
\hline P3 & A3 & M & PC diparético & $3^{\circ}$ ano $-\mathrm{EF}$ & $\begin{array}{l}\text { Cadeira e mesa } \\
\text { adaptadas, plano } \\
\text { inclinado, tesoura } \\
\text { mola, letras } \\
\text { imantadas. }\end{array}$ \\
\hline $\mathrm{P} 4$ & A4 & $\mathrm{F}$ & PC quadriparético & $1^{\circ}$ ano $-E F$ & $\begin{array}{l}\text { Cadeira e mesa } \\
\text { adaptadas, apoio } \\
\text { para os pés, } \\
\text { engrossador de lápis. }\end{array}$ \\
\hline P5 & A5 & M & PC diparético & $3^{\circ}$ ano $-E F$ & $\begin{array}{l}\text { Plano inclinado, } \\
\text { engrossador de lápis. }\end{array}$ \\
\hline P6 & A6 & $\mathrm{F}$ & PC hemiparético & $2^{\circ}$ ano $-\mathrm{EF}$ & Não utiliza. \\
\hline P7 & A7 & M & milemeningocele & $4^{\circ}$ ano $-E F$ & Não utiliza. \\
\hline P8 & A8 & $\mathrm{F}$ & PC atetose & $5^{\circ}$ ano $-E F$ & $\begin{array}{l}\text { Cadeira e mesa } \\
\text { adaptadas, plano } \\
\text { inclinado, colméia } \\
\text { para teclado, } \\
\text { boardmaker para } \\
\text { comunicaçáo } \\
\text { alternativa. }\end{array}$ \\
\hline P9 & A9 & $\mathrm{F}$ & $\begin{array}{l}\text { comprometimento } \\
\text { em membros } \\
\text { inferiores }\end{array}$ & $4^{\circ}$ ano $\mathrm{EF}$ & Não utiliza. \\
\hline
\end{tabular}

Fonte: Elaborada pelas autoras.

Constata-se que quatro alunos eram do sexo feminino e cinco do sexo masculino, a maior parte deles estavam inseridos no Ensino Fundamental e apresentavam diagnóstico de paralisia cerebral (7 alunos). Apenas uma professora (P9) não soube informar o diagnóstico de seu aluno, referindo-se ao comprometimento em membros inferiores.

Quanto aos recursos de TA, observa-se que o plano inclinado foi o mais prescrito para os alunos com DF. O seu uso pode favorecer o contato visual com a atividade, melhorar a funcionalidade dos membros superiores e da postura corporal. Outros recursos de TA estavam direcionados para a melhora da função manual, como a tesoura adaptada, o lápis engrossado e o engrossador de lápis, a colméia para teclado e as letras imantadas. Crianças com deficiência física podem apresentar dificuldades motoras para manipular os materiais, requerendo muitas vezes, a realização de adaptaçôes para facilitar o manuseio, promovendo maior independência nas atividades escolares (GONÇALVES; BRACCIALLI; CARVALHO, 2013). Adequaçôes no mobiliário também foram citadas (cadeira e mesa adaptadas e apoio para os pés) possi- 
velmente realizadas com o intuito de atender as necessidades posturais dos alunos e, consequentemente, favorecer o processo de ensino e aprendizagem. Destaca-se que apenas uma professora relatou adotar estratégia a fim de favorecer a comunicação do aluno, sendo esta através do boardmaker, um software que permite a construção de recursos de comunicação.

Apresenta-se, na Tabela 1, o grau de satisfação das professoras em relação à participação no processo que envolve o uso da TA. Tais informaçóes são acrescidas da frequência referente ao motivo do grau de sua satisfação.

Tabela 1 - Grau de satisfação das professoras em relação a TA

\begin{tabular}{|c|c|c|c|}
\hline $\begin{array}{c}\text { Grau de } \\
\text { Satisfaçáao }\end{array}$ & Frequência & Motivo & $\begin{array}{c}\text { Frenquência e } \\
\text { participantes }\end{array}$ \\
\hline Satisfação & 3 & $\begin{array}{l}\text { Parceria entre o professor } \\
\text { do AEE e outros } \\
\text { profissionais. } \\
\text { Favorece a aprendizagem } \\
\text { do aluno }\end{array}$ & $\begin{array}{l}2(\mathrm{P} 2 ; \mathrm{P} 8) \\
1(\mathrm{P} 3)\end{array}$ \\
\hline Pouco satisfeito & 2 & $\begin{array}{l}\text { Falta de conhecimento } \\
\text { sobre confecção de } \\
\text { recursos de baixo custo. } \\
\text { Falta de capacitação sobre } \\
\text { TA para os professores } \\
\text { do AEE }\end{array}$ & $\begin{array}{l}1(\mathrm{P} 5) \\
1(\mathrm{P} 1)\end{array}$ \\
\hline Pouco satisfeito & 0 & - & - \\
\hline Insatisfeito & 1 & $\begin{array}{l}\text { Ausência de interação } \\
\text { mais efetiva com os } \\
\text { profissionais que mantém } \\
\text { parceria }\end{array}$ & $1(\mathrm{P} 4)$ \\
\hline Muito insatisfeito & 0 & - & - \\
\hline $\begin{array}{l}\text { Não faz uso da } \\
\text { TA }\end{array}$ & 3 & - & 3 (P6, P7 E P9) \\
\hline
\end{tabular}

Fonte: Elaborada pelas autoras. 
Observa-se que das nove professoras investigadas, três estão satisfeitas com a sua participação no processo que envolve o uso da TA. Duas delas (P2 e P8) referem que a satisfação relaciona-se com a parceria mantida com profissionais de outras áreas de conhecimento. Esse é um dado relevante, pois mostra que o diálogo com profissionais de outras áreas pode contribuir para o compartilhamento de experiências e para a efetivação de um trabalho bem sucedido em prol do desenvolvimento educacional do aluno com deficiência.

Já P3, menciona que a satisfação se dá em função de perceber que o uso da TA tem favorecido a aprendizagem de seu aluno. É de suma importância que os professores de SRM tenham conhecimento acerca dos recursos de TA para que eles possam ser usados a fim de promover a autonomia dos alunos com necessidades educacionais especiais, eliminando desvantagens e limitaçóes que implicam no processo de aprendizagem (KAPITANGO-A-SAMBA; HEINZEN, 2014).

É interessante destacar que essa professora parece direcionar a sua atenção para as questôes do meio, e mostra que não está restrita ao olhar organicista da deficiência. Conforme apresentado no quadro 1 , seu aluno tem paralisia cerebral diparética, esta é caracterizada por comprometimento motor nos quatro membros, com predominância em membros inferiores (GAUZZI; FONSECA, 2004), tanto os membros inferiores quanto os superiores podem ser acometidos em graus variáveis de função motora, o que justifica os recursos utilizados por esse aluno. $\mathrm{O}$ mesmo utiliza mobiliário adaptado, sabe-se que o posicionamento adequado, favorecido pelas condiçóes apropriadas do mobiliário escolar, pode favorecer o desempenho funcional do aluno com DF durante as atividades realizadas em sala de aula e, possivelmente, tornar mais eficaz o processo de ensino e aprendizagem (PAULA; BALEOTTI, 2011). Além disso, esse aluno faz uso de plano inclinado e letras imantadas, os quais permitem o manuseio e o acesso ao símbolo gráfico para a formação de palavras, favorecendo o processo de alfabetização, uma vez que este não se dá pelo ato motor da escrita.

O processo de alfabetização é de natureza bastante complexa, envolve competências que viabilizam a alfabetização, como consciência fonológica; o princípio alfabético (ideia de que há uma relação entre a presença e posição de um grafema e o som que ele tem na palavra); a decodificação (capacidade de pronunciar o som de uma palavra escrita ou transformar em escrita uma palavra ouvida); entre outros. Ele tem princípio, meio e fim, e seu fim ocorre quando o aluno adquire o nível de fluência necessário para ter um mínimo de autonomia na leitura e escrita. (OLIVEIRA, 2005). Para este mesmo autor, escrever consiste em transcrever os sons da fala, o objetivo de escrever é comunicar.

Remetendo-nos ao aluno que possui como uma de suas condiçóes a deficiência física, sabe-se que esta pode afetar estruturas e funçóes corporais, e consequentemente, interferir no desempenho de atividades escolares. No entanto, embora tenham limitaçôes intrínsecas à sua condição, é essencial que o professor direcione a atenção para as possíveis limitaçóes que podem ser intrínsecas às demandas da atividade e/ ou das propriedades dos recursos pedagógicos e materiais escolares utilizados. Nessa 
perspectiva, a resoluçáo do problema de desempenho requer soluçóes que minimizem ou eliminem a discrepância entre o que a atividade exige para a sua realização em termos de competências funcionais e o que o aluno tem condiçóes de executar (BALEOTTI; ARAÚJO; SILVA, 2014).

Duas professoras ( $\mathrm{P} 1$ e P5) mostraram-se pouco satisfeitas. O motivo desse sentimento decorre da falta de conhecimento e capacitaçáo continuada sobre a TA. Matos (2012) em um estudo realizado com professores do AEE que atendiam alunos com surdocegueira encontrou resultados semelhantes ao deste estudo. $\mathrm{O}$ autor mencionou que, de acordo com os professores investigados, a especialização em AEE, e outras formaçôes não privilegiaram de forma ampliada e aprofundada o conteúdo específico que oferecesse suporte suficiente para atender alunos com surdocegueira. Cardoso (2013, p. 158) verificou em sua pesquisa que os professores de SRM tinham dificuldades para estabelecer " [...] um planejamento comprometido com a aprendizagem do aluno e capaz de auxiliar na identificação e seleção de metodologias e recursos para desenvolverem seu trabalho". No estudo desenvolvido por Rodrigues (2013) identificou-se a necessidade de um maior investimento na formação dos professores das SRM no que concerne ao uso da TA a fim de que eles possam usá-la com maior critério. A formação continuada de professores, de um modo geral, é um aspecto extremamente importante, visto que as atribuiçóes do professor são fundamentais para a implementação da pedagogia inclusiva (GIROTO; POKER; OMOTE, 2012).

Uma professora (P4) referiu estar insatisfeita quando questionada sobre sua participação nos procedimentos que envolvem a TA, devido à falta de retorno por parte dos profissionais que mantém parceria. Constata-se no quadro 1 , que seu aluno apresenta paralisia cerebral do tipo quadriplégica, a qual é compreendida como uma das formas mais graves de paralisia cerebral do ponto de vista motor. Caracterizase por grave comprometimento nos quatro membros e déficit no controle cervical. Embora seu aluno faça uso de recursos de TA, importantes no âmbito escolar, tais como mobiliário e mesa adaptados, a professora (P4) relata que náo tem o retorno necessário dos profissionais. Se por um lado a literatura aponta que a parceria ou a consultoria colaborativa é importante, por outro lado, tem que se investigar que tipo de parceria se faz necessária, bem como a forma que, de fato, a parceria está se efetivando. Não é possível estabelecer generalizaçôes com base na fala de apenas uma das participantes. Porém, trata-se de um dado relevante que merece ser investigado a fim de favorecer as reflexões e discussões sobre essa temática.

Três professoras (P6, P7 e P9) relataram que não usavam recursos da TA junto aos alunos com DF que atendiam. Em conversa informal mantida com essas professoras elas informaram que os alunos que atendiam no AEE apresentavam déficit motor em membros inferiores, e o comprometimento cognitivo relacionava-se ao déficit de memória e fala infantilizada. No entanto, salientaram que seus alunos tinham mobiliário adaptado e estavam posicionados corretamente para o desenvolvimento das atividades pedagógicas. Tais dados sinalizam que, possivelmente, essas professoras não têm conhecimento suficiente sobre a TA, pois o mobiliário adaptado é um dos itens que faz parte da TA. Esses dados sinalizam a necessidade de formação continu- 
ada que dê subsídios para que os professores do AEE se apropriem do conhecimento teórico e prático que fundamentam à tecnologia assistiva na Educação Especial, na perspectiva da Educação Inclusiva.

$\mathrm{Na}$ sequência, são apresentados os dados relativos à parceria do professor do AEE com profissionais de outras áreas de conhecimento no processo que envolve o uso do recurso de TA. Esses dados podem ser visualizados no Quadro 2.

Quadro 2 - Parceria do professor de AEE com outros profissionais frente a TA para o aluno com DF

\begin{tabular}{|c|l|}
\hline Participantes & \multicolumn{1}{c|}{ Outros profissionais } \\
\hline P1 & \multicolumn{1}{|c|}{ Profissionais do CEMAEE $^{3}$} \\
\hline P2 & Fisioterapeuta e Terapeuta Ocupacional \\
\hline P3 & Não tem parcerias \\
\hline P4 & Fonoaudiólogo e Terapeuta Ocupacional \\
\hline P5 & Não tem parcerias \\
\hline P6 & Não tem parcerias \\
\hline P7 & Profissionais do CEMAEE \\
\hline P8 & Fisioterapeuta e Fonoaudiólogo \\
\hline P9 & Profissionais do CEMAEE \\
\hline &
\end{tabular}

Fonte: Elaborada pelas autoras.

De acordo com o Quadro 2, constata-se que três professoras (P3, P6 e P6) informaram náo ter parcerias com outros profissionais. Embora o questionamento deu-se exclusivamente em relação à parceria para a implementaçáo da TA, cabe salientar que a aproximação com outros profissionais não se restringe ao apoio no que concerne ao uso do recurso da TA, mas pode englobar discussóes relativas à variedade de aspectos que envolvem o processo de ensino e aprendizagem do aluno com deficiência, com vistas à implementação de estratégias que visem favorecer o ensino inclusivo para esse aluno.

Destaca-se que P5, além de não ter parceria com outros profissionais, não possui pós-graduação na área da Educação Especial, e considera-se pouco satisfeita com sua participaçáo na prescrição do recurso de TA. A falta de formaçáo continuada na área e a impossibilidade de diálogo com outros profissionais são aspectos, que, provavelmente, interferem na prática pedagógica do professor que realiza o AEE para $\mathrm{o}$ aluno com deficiência física. $\mathrm{O}$ aluno com deficiência física que frequenta salas de SRM, provavelmente necessitará de recursos da TA, tais como equipamentos, mobiliários e materiais didáticos e pedagógicos adaptados. Para a utilizaçáo desses recursos é imprescindível conhecimento prévio e abrangente que envolve: 
[...] avaliaçáo; a seleção do recurso mais apropriado a cada caso; o ensino do usuário sobre a utilização de seu recurso; o acompanhamento durante a implementação da TA no contexto de vida real; as reavaliaçóes e ajustes no processo. (BERSCH, 2013, p. 12).

As demais professoras (seis), conforme apresentado no quadro 2, relataram ter parcerias com diferentes profissionais tais como fisioterapeutas, fonoaudiólogos, psicólogos, pedagogos e terapeutas ocupacionais. Destaca-se que P8 apesar de não possuir pós-graduação na área da Educação Especial recebe o apoio de profissionais da área da saúde e atribui a essa parceria a satisfação em relação ao processo de seleção, indicação, treinamento e acompanhamento do uso do recurso de TA. Galvão Filho (2009) enfatiza a necessidade de a escola possuir suporte técnico desde a fase de implantação da TA até as fases de acompanhamentos, ajustes, personalização e revisóes para que a TA utilizada não seja abandonada e para o sucesso de seu uso. A literatura traz estudos que mostram a importância da parceria para a elaboração do recurso pedagógico adaptado (SAMESHIMA; RODRIGUES; DELIBERTADO, 2009; SAMESHIMA, 2011).

Na mesma direção, Cortelazzo, Rocha e Di Palma (2007) pontuam que o trabalho em equipe e o uso da TA são elementos fundamentais que podem ajudar o professor à prática inclusiva efetiva. Rocha e Deliberato (2012) enfatizam que a parceria do professor com profissionais da saúde, relativo ao uso da TA, deve se efetivar nas diferentes etapas do serviço, sendo elas avaliação e identificação das habilidades e necessidades do aluno com disfunçáo física, prescrição e confecção dos recursos, e acompanhamento por profissionais envolvidos na parceria.

A Legislação aponta que para a utilização de determinados recursos é necessário o parecer técnico de um fisioterapeuta ou de um terapeuta ocupacional, no sentido de verificar se o material está adequado às necessidades especiais do aluno e se o aluno está apto para utilizá-lo (SILVA; CASTRO; BRANCO, 2006). É importante que as escolas busquem, sempre que possível, orientaçóes de profissionais especializados para realizar adequaçóes necessárias ao desenvolvimento dos alunos com deficiência.

\section{Conclusão}

Muitos são os desafios encontrados no cotidiano escolar para que a inclusão se dê de maneira efetiva. Um desses desafios tem relação com o uso da tecnologia assistiva, a qual exige conhecimento prévio que subsidie a sua utilização junto aos alunos com deficiência. A opiniấo dos professores do AEE sobre a TA é fundamental para a reavaliação das práticas pedagógicas em curso e, além disso, permite identificar as dificuldades vivenciadas para a implementação da TA.

Os resultados obtidos neste estudo apontam para a necessidade do investimento em formação continuada que contemple conteúdo específico sobre tecnologia assistiva para o aluno com deficiência física. Não basta ao professor o acesso ao recurso da TA, ele necessita ter conhecimento específico para que possa fazer uso eficaz dele. 
Além disso, os resultados sugerem que a parceria entre os profissionais de outras áreas de conhecimento e o professor do AEE é uma medida necessária para o processo de identificação, elaboração, produção e acompanhamento da funcionalidade dos recursos da TA. Por outro lado, os resultados apontam para a importância de se investigar como as diferentes parcerias estáo sendo implementadas no contexto escolar, e suscitam reflexóes sobre qual a melhor maneira de se efetivá-las a fim de intensificar os seus benefícios para os alunos com deficiência. Para que o processo de trabalho colaborativo seja eficaz e benéfico para todos, ele deve estar pautado numa relação igualitária e vislumbrar, sobretudo, a resolução dos desafios que emergem no cotidiano escolar perante a inclusão de alunos com deficiências.

\section{Referências}

ANJOS, H. P.; ANDRADE E. P.; PEREIRA, M. R. A inclusão escolar do ponto de vista dos professores: o processo de constituição de um discurso. Revista Brasileira de Educação, v. 40, n. 40, p. 117-129, 2009.

BALEOTTI, L. R.; ARAÚJO, R. C. T.; SILVA, N. R. Terapia Ocupacional e Educaçấo Especial. In: GIROTO, C. R. M.; DEL MASSO, M. C. S.; MILANEZ, S. G. C. et al. (Org.). Serviços de apoio em Educaçáo Especial: um olhar para diferentes realidades. Alcalá de Henares: Editora Universitária Internacional, da Universidade de Alcalá, 2014. v. 2.

BERSCH, R. Introduçáo à tecnologia assistiva. Assistiva- Tecnologia e Educação. Porto Alegre, RS, 2013. Disponível em: <http://www.assistiva.com.br/Introducao_Tecnologia_Assistiva.pdf>. Acesso em: 26 out. 2015.

BRASIL. Decreto no $\mathbf{5 . 2 9 6}$ de 2 de dezembro de 2004. Regulamenta as Leis nos 10.048, de 8 de novembro de 2000, que dá prioridade de atendimento às pessoas que especifica, e 10.098, de 19 de dezembro de 2000, que estabelece normas gerais e critérios básicos para a promoção da acessibilidade das pessoas portadoras de deficiência ou com mobilidade reduzida, e dá outras providências. Diário Oficial da República Federativa do Brasil. Brasília, dez. 2004. Disponível em: <http://portal.mec.gov.br/seesp/arquivos/pdf/decreto\%205296-2004.pdf>. Acesso em: 23 jan. 2017.

BRASIL. Ministério da Educação. Secretaria de Educação Especial. Política Nacional de Educação especial na perspectiva da educação Inclusiva. Brasília, DF, 2008. Disponível em: <http://peei.mec.gov.br/arquivos/ politica_nacional_educacao_especial.pdf>. Acesso em: 10 dez. 2014.

BRASIL. Ministério da Educação. Conselho Nacional de Educação. Câmara de Educação Básica. Resolução n. 4, de 2 de outubro de 2009. Institui Diretrizes Operacionais para o Atendimento Educacional Especializado na Educaçáo Básica, modalidade Educaçáo Especial. Brasília, DF, 2009. Disponível em: < http://portal. mec.gov.br/dmdocuments/rceb004_09.pdf>. Acesso em: 23 jan. 2017.

BRASIL. Ministério da Educação. Conselho Nacional de Educação. Câmara de Educação Básica. Resolução n. 4, de 13 de julho de 2010. Define Diretrizes Curriculares Nacionais Gerais para a Educaçáo Básica. Brasília, DF, 2010. Disponível em: <http://portal.mec.gov.br/dmdocuments/rceb004_10.pdf>. Acesso em: 10 dez. 2014

BRASIL. Decreto n. 7.611, de 17 de novembro de 2011. Dispóe sobre a educaçáo especial, o atendimento educacional especializado e dá outras providências. Diário Oficial da União, Brasília, DF, 18 nov. 2011. Disponível em: <http://www.planalto.gov.br/ccivil_03/_ato2011-2014/2011/decreto/d7611.htm>. Acesso em: 10 dez. 2014.

CARDOSO, C. R. Organizaçáo do trabalho pedagógico, funcionamento e avaliaçáo no atendimento educacional especializado em salas de recursos multifuncionais. 2013. 188f. Dissertação (Mestrado em Educação) - Universidade Federal de Goiás, Cataláo, 2013.

COMITÊ DE AJUDAS TÉCNICAS. Tecnologia Assistiva. Brasília, DF: SEDH, 2009. Disponível em: http:// www.pessoacomdeficiencia.gov.br/app/sites/default/files/publicacoes/livro -tecnologia- assistiva.pdf. Acesso em: 15 out. 2015.

CORTELAZZO, I. B. C.; ROCHA, C. A.; DI PALMA, M. S. Formação de professores para educação especial: Educação inclusiva com o apoio das Tecnologias Assistivas. In: CONGRESSO BRASILEIRO MULTIDISCIPLINAR DE EDUCAÇÃO ESPECIAL, 4., 2007, Londrina. Anais...2007. 
GALVĀO FILHO, T. A. Tecnologia assistiva para uma escola inclusiva: apropriaçấo, demanda e perspectivas. 2009. 346f. Tese (Doutorado em Educação) - Universidade Federal da Bahia, Salvador, 2009.

GAUZZI, L. D. V.; FONSECA, L. F. Classificação da paralisia cerebral. In: LIMA, C. L. A.; FONSECA, L. F. Paralisia cerebral: Neurologia, ortopedia, reabilitaçáo. Rio de Janeiro: Medsi/Guanabara Koogan, 2004.

GHEDINI, L. S. L.; MANCINI, M. C.; BRANDĀO, M. B. Participação de alunos com deficiência física no contexto da escola regular- Revisão de Literatura. Revista de Terapia Ocupacional da Universidade de Sáo Paulo, v. 21, n. 1, p. 1-9, jan./abr. 2010.

GIROTO, C. R. M. Atuação fonoaudiológica na educação inclusiva. In: MARCHESAN, I. Q.; SILVA, H. J.; TOMÉ, M. C. (Org). Tratado de especialidades em fonoaudiologia. São Paulo: Guanabara Koogan, 2014. p. 497-505.

GIROTO, C. R. M.; POKER, R. B.; OMOTE, S. Educação Especial, formaçăo de professores e o uso de tecnologias de informação e comunicação: a construção de práticas pedagógicas inclusivas. In: As tecnologias nas práticas pedagógicas inclusivas. Marília: Cultura Acadêmica, 2012. p. 12-22. Disponível em: https://www. marilia.unesp.br/home/publicacoes/as-tecnologias-nas-praticas_e-book.pdf. Acesso em: 13 out. 2015.

GLAT, R.; PLETSCH, M. D.; FONTES, R. S. Educação inclusiva \& educaçâo especial: propostas que se complementam no contexto da escola aberta à diversidade. Educaçáo, Santa Maria, v. 32, n. 2, p. 343-356, 2007.

GONCALVES, A. G.; BRACCIALLI, L. M. P.; CARVALHO, S. M. R. Desempenho motor de aluno com paralisia cerebral discinética frente à adaptação das propriedades físicas de recurso pedagógico. Revista Brasileira de Educaçáo Especial, v. 19, n. 2, p. 257-272, 2013.

KAPITANGO-A-SAMBA, K. K. HEINZEN, V. A. Formação de professores em tecnologia assistiva para atendimento educacional especializado em salas de recursos multifuncionais: inclusão ou exclusão? Revista de Educaçáo do Vale do Arinos, Universidade do Estado de Mato Grosso - UNEMAT (Juara), n. 1, v. 1, 2014.

MATOS, I. S. Formaçáo continuada dos professores do AEE- saberes e práticas pedagógicas para a inclusáo e permanência de alunos com surdocegueira na escola. 2012. 220 f. Dissertaçáo (Mestrado em Educação) - Universidade Estadual do Ceará, Fortaleza, 2012.

MELO, F. R. L. V.; PEREIRA, A. P. M. Inclusão escolar do aluno com deficiência física: visão dos professores acerca da colaboração do fisioterapeuta. Revista Brasileira de Educaçáo Especial, Marília, v. 19, n.1, p. 93 106, jan./ mar. 2013.

OLIVEIRA, J. B. A. Avaliação em alfabetização. Ensaio: Avaliação e Políticas Públicas em Educação, v.13, n. 48, p. 375-382, 2005.

PAULA, A. F. M.; BALEOTTI, L. R. Inclusão escolar do aluno com deficiência física: contribuições da Terapia Ocupacional. Cadernos de Terapia Ocupacional da UFSCar, São Carlos, v. 19, n. 1, p. 53-69, 2011.

PELOSI, M. B.; NUNES, L. R. D. P. Caracterização dos professores itinerantes, suas açôes na área de tecnologia assistiva e seu papel como agente de inclusão escolar. Revista Brasileira de Educaçáo Especial, Marília, v.15, n.1, p.141-154, jan.-abr. 2009

ROCHA, A. N. C.; DELIBERATO, D. Tecnologia assistiva para a criança com paralisia cerebral na escola: identificação das necessidades. Revista Brasileira de Educaçáo Especial, v. 18, n. 1, 2012.

ROCHA, E. F.; LUIZ, A.; ZULIAN, M. A. R. Reflexôes sobre as possíveis contribuiçóes da terapia ocupacional nos processos de inclusão escolar. Revista de Terapia Ocupacional da Universidade de São Paulo, São Paulo, v. 14, n. 2, p. 72-8, 2003.

RODRIGUES, M. E. N. Avaliaçáo da tecnologia assistiva na sala de recursos multifuncionais: estudo de caso em Fortaleza - Ceará. 2013. 111f. Dissertação (Mestrado em Educação) - Faculdade de Educação, Universidade Federal do Ceará, Fortaleza, 2013.

RODRIGUES, P. R.; ALVES, L. R. G. Tecnologia Assistiva - uma revisão do tema. Holos, v. 6, 2013.

SAMESHIMA, F. S. Capacitaçáo de professores no contexto de sistemas de comunicaçáo suplementar e alternativa. 2011. 173 f. Tese (Doutorado em Educação) - Faculdade de Filosofia e Ciências, Universidade Estadual Paulista, Marília, 2011.

SAMESHIMA, F. S.; RODRIGUES, I. B.; DELIBERATO, D. A parceria entre especialistas, professor e família no processo de implementaçáo da comunicaçáo alternativa: uma condiçáo necessária. In: $\mathrm{V} C \mathrm{CON}$ GRESSO BRASILEIRO MULTIDISCIPLINAR DE EDUCAÇÃO ESPECIAL, 2009, Londrina. Anais... Londrina: UEL, 2009. 
SILVA, A. F.; CASTRO, A.L.B.; BRANCO, M.C.M.C. A inclusão escolar de alunos com necessidades educacionais especiais: deficiência física. Brasília: Ministério da Educação, Secretaria de Educação Especial, 2006.

VITTA, F. C. F.; SILVA, K. P. L; MORAES, M. C. A. F. Conceito sobre a educação da criança deficiente, de acordo com professores de educação infantil da cidade de Bauru. Revista Brasileira de Educaçáo Especial, Marília, v. 10, n.1, p.43-58, jan./abr.2004.

ZAFANI, M. D. Percepçáo de pais e professores acerca do desempenho de crianças com deficiência física em atividades do contexto escolar. 2013. 221 f. Dissertação (Mestrado em Educação) - Faculdade de Filosofia e Ciências, Universidade Estadual Paulista, Marília, 2013.

\section{Notas}

${ }^{1}$ Paralisia Cerebral

${ }^{2}$ Ensino Fundamental

3 CEMAEE: Centro Municipal de Atendimento à Educaçáo Especial. Equipe composta por fisioterapeuta, fonoaudiólogo, psicólogo, terapeuta ocupacional e pedagogo.

\section{Correspondência}

Luciana Ramos Baleotti - Faculdade de Filosofia e Ciências da Universidade Estadual Paulista. Rua: Av. Higino Muzi Filho, 737, Mirante, Marília, São Paulo, Brasil.

E-mail: baleotti@marilia.unesp.br - carolinaperez.to@gmail.com - mari_dzafani@hotmail.com

Correspondência em 19 de julho de 2016

Final em 20 de março de 2018 
